\title{
Inner-City Children's Exposure to Community Violence: How Much Do Parents Know?
}

This study examines the psychological impact of children's exposure to violence and the influence of mothers' knowledge about their children's encounters with violence. Our sample consists of a poor, multiethnic sample of 104 fourth-or fifthgrade children and their mothers. Children in this sample were exposed to rather high levels of community violence, and on the whole, mothers greatly underestimated their children's exposure to violence and feelings of psychological distress. Hierarchical regression analyses indicated that children's exposure to violence was associated with greater psychological distress. Our findings suggest that the detrimental effects of community violence are present for all children, irrespective of their racial background. Further, greater mother-child agreement about children's exposure to violence was related to better psychological functioning. The implications of these results for effective parenting strategies and community-based interventions are discussed.

It is an unfortunate yet all too common fact that many poor, inner-city children are continuously and chronically exposed to community violence. Whereas the nation publicly mourns the shootings at schools such as Columbine, life-threatening violence is a daily obstacle for many children in

Department of Psychology, University of Michigan, 525 East University, Ann Arbor, MI 48109.

Key Words: community violence, parenting, psychological well-being, vicarious victimization. impoverished urban families. It is not simply adolescents residing in cities, but even young, elementary school-aged children who report exceedingly high rates of exposure to violence (Richters \& Martinez, 1993; Schwab-Stone et al., 1999; Singer, Anglin, Song, \& Lunghofer, 1995). Moreover, exposure to community violence has many negative repercussions for children's mental health (Bell \& Jenkins, 1991; Fitzpatrick \& Boldizar, 1993; Hill \& Madhere, 1996). Random innercity violence has thus emerged as a problem of paramount importance in many poverty-stricken urban neighborhoods. Consequently, our approach to this study is consistent with Bronfenbrenner's (1986) ecological perspective that contextual variables will affect family processes and children's developmental pathways. Despite widespread acceptance of this theory, it has not been until relatively recently that researchers have focused attention on the impact of community violence in urban neighborhoods.

The purposes of the present paper are threefold. The first goal is to document rates of exposure to violence among a poor, multiethnic sample of fourth- and fifth-grade children and to investigate the extent of mothers' knowledge about their children's exposure to urban violence and the psychological effects of that violence. Second, we will explore whether several individual child and parent characteristics are related to poor mothers' knowledge of their children's exposure to violence. Finally, we will use hierarchical regression analyses to investigate how children's exposure to 
violence, vicarious experiences of victimization, fear of crime, and mothers' knowledge of children's violence exposure are related to children's psychological functioning. Parental awareness of children's exposure to community violence may have important implications for effective parenting behavior and for the development of interventions that assist parents in helping their children to cope with the psychological effects of urban violence.

\section{The Psychological Impact of Children's EXPOSURE TO VIOLENCE}

Evidence of children's exposure to community violence in poor urban neighborhoods is provided by numerous investigations. In a sample of 170 fifth and sixth graders attending a metropolitan school system, over $80 \%$ reported regularly hearing the sounds of gunfire in their neighborhoods, and one in every six of these children reported having witnessed a homicide (Lorion \& Saltzman, 1993). Gladstein, Rusonis, and Heald (1992) found that in a group of 403 inner-city adolescents, $9 \%$ reported that they themselves had been assaulted with a weapon, and $22 \%$ reported that their lives had been threatened. These figures are in sharp contrast to their comparison sample of 435 upper-middle-class youths. In this latter group, $2 \%$ reported that they had been assaulted with a weapon, and $12 \%$ had had their lives threatened. In a large, urban sample of over 3,500 high school students, $82 \%$ of the adolescents reported incidents of witnessing community violence (Singer et al., 1995). Taken together, these and many other findings provide compelling documentation of the high rates of chronic exposure to urban violence facing many poor, inner-city children.

Exposure to community violence is consequently related to a host of detrimental outcomes, including a wide array of behavioral and psychological difficulties. Several studies have specifically found that children's exposure to violence increases their susceptibility to externalizing behavior problems (Cooley-Quille, Turner, \& Beidel, 1995; Gorman-Smith \& Tolan, 1998; SchwabStone et al., 1999) and general anxiety and distress (Hill \& Madhere, 1996; Singer et al., 1995). Moreover, Schwab-Stone and colleagues reported that a relation between adolescents' exposure to violence and externalizing behavior was maintained over a 2-year time period. Additionally, a number of studies indicate that children who are exposed to chronic community violence manifest symptoms that are indicative of every diagnostic criterion of posttraumatic stress disorder (PTSD; Bell \& Jenkins, 1991; Gladstein et al., 1992; Lorion \& Saltzman, 1993; Pynoos \& Nader, 1990, 1988). In children, PTSD symptoms may include the following: reexperiencing traumatic events in dreams and play, constricted affect, diminished interest in once pleasurable activities, startle reactions, sleep problems, and avoidance behaviors.

We contend that it is not simply direct experiences with violence that have a detrimental effect on children's well-being but that living with an ever-present threat of random violence and the vicarious experiences of others' victimization may also affect children's psychological functioning. Hill and Madhere (1996) reported that violence apprehension was related to anxiety and confrontational behavior among 150 African American children. Likewise, Jenkins and Bell (1994) found that children who reported feeling unsafe on their way to school also reported higher levels of psychological distress. Fear of crime may be further compounded by children's vicarious experience of violence via friends and family members. Indeed, children often know the victims of crime in their communities. Among 1,000 Chicago students, $39 \%$ reported witnessing a shooting, and $50 \%$ of the shooting victims were known to the children as friends, classmates, neighbors, or family members (Bell \& Jenkins, 1993). In a sample of Baltimore adolescents, over $45 \%$ reported knowing someone who had been assaulted with a weapon, robbed, knifed, or murdered, and $67 \%$ reported knowing someone who had been shot (Gladstein et al., 1992). Thus, it is conceivable that children experience distress caused by a pervasive fear of violence and secondary trauma via their relationship with a friend or family member who has been victimized (Jenkins \& Bell).

\section{Parenting Children in a Context of POVERTY AND URBAN Violence}

The challenges facing parents in impoverished, high-risk neighborhoods are numerous. Although the links between children's violence exposure and psychological difficulties have been well documented, less attention has been focused on parents' awareness of the environmental dangers facing their children. In a sample of 96 children, ages 9 to 12 years, Hill and Jones (1997) reported striking discrepancies between parents' and children's perceptions of children's exposure to violence. 
Whereas the majority of parents indicated that their children had not been exposed to any incidents of violence, only $15 \%$ of the children gave concurring reports. Martinez and Richters compared child and parent reports of children's violence exposure and distress symptoms among a sample of 165 children, ages 6 to 10 years (Martinez \& Richters, 1993; Richters \& Martinez, 1993). They similarly found that parents generally underestimated children's reports of violence exposure and emotional distress. A lack of awareness about children's violence exposure may impair parents' ability to effectively monitor and supervise their children. In fact, several investigators identify close monitoring and supervision as an especially efficacious strategy among parents whose children face environmental risks and adversity (Baldwin, Baldwin, \& Cole, 1990; Mason, Cauce, Gonzales, \& Hiraga, 1996; Pettit, Bates, Dodge, \& Meece, 1999).

Several factors are likely to influence parents' knowledge about their children's daily experiences and emotional well-being. Such factors may include, but are not limited to, employment schedules, financial stress, number of children in the household, and the quality of parent-child relationships. On the whole, parental knowledge and the tracking of children's daily experiences is demarcated as mothers' work, and mothers tend to know more about their children's activities than fathers do (Crouter, Helms-Erikson, Updegraff, \& McHale, 1999). Crouter, MacDermid, McHale, and Perry-Jenkins (1990) reported no association between the extent of mothers' work hours and their knowledge about school-aged children's daily activities in a middle-class sample of families. However, parents did know more about their younger, second-born children than their older, first-born children, who were 8 and 11 years old, respectively (Crouter et al., 1999). In addition, both parents were generally inclined to have more knowledge about children of their own sex.

Whereas most studies investigating the effects of exposure to community violence have been conducted with poor, African American samples (DuRant, Getts, Cadenhead, Emans, \& Woods, 1995; Fitzpatrick, 1993), the current study relied on a multiethnic sample of families. Indeed, poor African Americans are frequently concentrated in impoverished neighborhoods where social, educational, and occupational resources are few and where high crime rates are common (McLoyd \& Ceballo, 1998). Like African Americans, Latino families are disproportionately disadvantaged in economic resources. In 1998, more than half of the nation's Latino households lived in central cities of metropolitan areas, and 34\% of Latino children under 18 years of age were living in poverty (U.S. Census Bureau, 1999). It may be that the negative consequences of exposure to violence are drastic enough to affect all children similarlyirrespective of their racial backgrounds. Alternatively, cultural differences may moderate the degree and effects of violence exposure. For instance, a common emphasis on family solidarity among Latinos may limit children's street-culture activities (Zayas \& Solari, 1994). On the other hand, Gorman-Smith, Tolan, Zelli, and Huesmann (1996) reported that African American families monitored their children's activities more closely than Latino parents did.

Overall, we expect our results to concur with the findings of Richters and Martinez (1993) and of Hill and Jones (1997). We hypothesize that mothers in our study will similarly underestimate the extent of children's exposure to inner-city violence and psychological distress. Additionally, we expect that mothers' knowledge and therefore agreement with children about their violence exposure will be highest for younger children, who are more easily supervised (Crouter et al., 1999), and for female children, who typically report less involvement in street-culture activities than do boys (Bell \& Jenkins, 1993; Fitzpatrick \& Boldizar, 1993). We will also explore whether mothers' knowledge is related to several parental characteristics, such as mothers' age, employment, marital status, education, number of children, and immigrant status. Finally, in keeping with the literature, we hypothesize that greater exposure to violence, fear of crime, and vicarious experiences of violence will be related to greater psychological distress in children. Likewise, we predict that greater maternal reports of children's violence exposure and lower mother-child agreement about the degree of children's violence exposure will be associated with impaired psychological functioning, because more limited knowledge of children's activities may reflect diminished levels of parental interest and lower parent-child relationship quality (Crouter et al., 1999).

\section{MethoD}

\section{Sample}

The sample consisted of 104 matched pairs of fourth or fifth graders and their mothers or legal 
Table 1. Demographic Characteristics of Mothers

\begin{tabular}{|c|c|}
\hline Characteristic & $n$ \\
\hline \multicolumn{2}{|l|}{ Race } \\
\hline Latina & 53 \\
\hline European American & 35 \\
\hline African American & 13 \\
\hline Other & 3 \\
\hline \multicolumn{2}{|l|}{ Marital status } \\
\hline Married & 56 \\
\hline Separated or divorced & 23 \\
\hline Single & 25 \\
\hline \multicolumn{2}{|l|}{ Education } \\
\hline No high school degree & 48 \\
\hline High school degree or GED & 28 \\
\hline Trade school or some college & 24 \\
\hline College degree & 4 \\
\hline \multicolumn{2}{|l|}{ Employment } \\
\hline Full-time & 48 \\
\hline Part-time & 19 \\
\hline No current employment & 37 \\
\hline \multicolumn{2}{|l|}{ Personal income } \\
\hline Under $\$ 10,000$ & 49 \\
\hline$\$ 10,000-19,999$ & 25 \\
\hline$\$ 20,000-29,999$ & 14 \\
\hline Over $\$ 30,000$ & 12 \\
\hline \multicolumn{2}{|l|}{ Ever on welfare } \\
\hline Yes & 74 \\
\hline No & 30 \\
\hline
\end{tabular}

Note: The number of cases for each variable may vary slightly because missing cases are excluded. Mean age of mothers was 36 years $(S D=6.82)$. Mean number of children was $3.3(S D=1.42)$, and mean number of people in home was $4.99(S D=1.59)$.

female guardians. Demographic characteristics of the sample were obtained during the initial interview stage and are displayed in Table 1 . There were 56 female and 48 male children in this sample, with a mean age of 10 years. Sixty-three children identified themselves as Latinos, with the majority of these children reporting a Mexican American ethnicity. In addition, 24 children were of European descent, and 14 were African American.

We interviewed 93 biological mothers, 7 grandmothers, and 4 legal guardians, all of whom had primary parenting responsibility for their children. (For the rest of the paper, all of the women interviewed will be referred to as mothers.) The mothers had a mean age of 36 years and an average of 3.3 children. Thirty-six percent of the mothers were unemployed, and 54\% were married. Overall, these mothers represent an extremely impoverished sample, as indicated by the $71 \%$ who reported an annual personal income under $\$ 20,000$, the $71 \%$ who reported that they had at some time been on welfare, and the $46 \%$ who did not have a high school diploma. Further, mothers categorized their median household incomes as falling within the range of $\$ 20,000$ to $\$ 25,000$. The mothers also represented a multiethnic group, with 53 Latina, 35 European American, 13 African American, and 3 racially unidentified mothers. Among the Latina mothers, the majority were of Mexican American descent, 34 were not born in the United States, and 96\% spoke Spanish in their homes.

\section{Procedure}

On two separate occasions, parental recruitment letters describing the study along with consent forms were sent home with all of the fourth- and fifth-grade children in two Detroit elementary schools. The schools were located in a poor, highrisk neighborhood corresponding to two census tracts that had median household incomes of $\$ 14,257$ and $\$ 15,057$, respectively, and $32 \%$ and $42 \%$ of the population living below the poverty line in 1989 (U.S. Census Bureau, 1990). Further, FBI crime statistics indicate that in 1997 the number of violent crimes (murder, rape, robbery, and assault) reached a total of 2,151 per 100,000 people in Detroit, as compared to the national average of 634 violent crimes per 100,000 people (Federal Bureau of Investigation, 1997). Among the eligible students, $77 \%$ of the children in one school and $58 \%$ of the children in the other school returned signed consent forms. With only two delivery attempts, and considering the unreliability with which young children deliver materials to their parents, our response rates are respectable among this population of poor, highly stressed families. (Recruitment efforts in one school occurred at the end of the academic year, when families were preoccupied with school ceremonies and summer plans. This may partially account for our lower response rate in that school.)

Questionnaires were administered to the 163 children who returned their consent forms. In our entire sample of 163 children, none of the children lived with male kin only; all of the children reported at least one female relative in the home. The children were interviewed in a small-group format in which graduate and undergraduate students read the questionnaires out loud to groups of two to five children, who followed along and answered the questions as they went. Interviews 
were conducted at the schools and took approximately 2 hours (with the inclusion of several breaks). For eight children who indicated that they preferred to speak Spanish, the questionnaire had been translated and back-translated into Spanish, and these children worked with a bilingual graduate student. At one school, children who participated in the study received a $\$ 20$ gift certificate to Toys-R-Us; in the other school, children attended a "pizza party" because the school principal preferred that children not receive monetary compensation for research participation.

Upon completion of the child data collection, mothers of the children were contacted and recruited by phone. Out of 163 children interviewed, 15 children also had a sibling participating in the study, resulting in a total of 148 mothers available for participation. Seventy percent of these eligible mothers were interviewed. The sample for this study includes only those children whose mothers were also interviewed, resulting in a final sample of 104 mother-child pairs. On all of our child measures, we conducted $t$ tests between children whose mothers did participate in the study and children whose mothers did not participate. No significant differences emerged to indicate a selection bias between the mother-child pairs who did, versus those who did not, agree to participate. Mothers were interviewed in local fast-food restaurants or in their homes, and the mother interviews lasted about 2 hours. All mothers were paid $\$ 50$ for their assistance and participation. For 26 mothers who preferred to have the interview conducted in Spanish, a mother questionnaire, which had been translated by a bilingual professional associated with one of the schools and then back-translated, was administered by a bilingual research assistant.

\section{Measures}

The Survey of Exposure to Community Violence (Richters \& Martinez, 1993) measures the frequency of lifetime exposure to 25 different types of violence. (Two items from the original measure were excluded because school officials were not comfortable with their sexual content.) Children were asked to report how many times they were victims or witnesses of certain violent events on a scale from 0 (never) to 11 (almost every day). Two scales were constructed to reflect a measure of personal victimization and witnessing violence. The scale of personal victimization $(\alpha=.84)$ was created by adding children's scores on 10 items that assessed personal experiences with violent events, such as being "threatened with serious physical harm" and "attacked or stabbed with a knife." The scale for witnessing violent events $(\alpha$ $=.87$ ) consisted of summing scores on 10 items that involve witnessing incidents, such as seeing "someone else getting beaten up or mugged" and seeing "someone else get shot with a gun." Higher scores on these scales reflect a greater frequency of exposure to community violence, as either victims or witnesses.

The same measure of exposure to community violence was adapted for use with the children's mothers. For each of the 10 types of violent incidents in the personal victimization and witnessing violence scales, mothers were asked whether their child had ever experienced such a violent event. Mothers were not asked to comment on the frequency of their children's exposure to these incidents, but rather to indicate whether their child had (1) or had not (0) ever been exposed to such violence. Two scales, of personal victimization $(\alpha$ $=.56)$ and of witnessing violence $(\alpha=.74)$, were similarly created for mothers' reports based on an additive count of the number of incidents mothers reported their children as ever having experienced.

Mother-child agreement on violence exposure was measured by assigning mothers a score of 1 if their answers about their child's exposure to a violent incident (yes/no) matched a dichotomous (never/at least once) recoding of their child's answers for that same event. If mothers' answers did not match their children's answers regarding a particular violent event, they received a score of 0 . Two scales of mother-child agreement were constructed in this manner, one indicating correspondence on personal victimization items and the other on witnessing violent events. On each scale, mothers' scores could thus range from 0 (no agreement) to 10 (perfect agreement), with higher scores reflecting greater agreement between mother and child reports of child's exposure to violence.

Vicarious violence exposure tapped information about children's relationships to victims of violent crimes, specifically close friends and family members. Children were asked how many of their close friends and family members had experienced any one of nine types of violent incidents at any time in their lives. These questions were developed and used by Jenkins and Bell (1994). Examples of the violent incidents included muggings, attacks with a knife, and being at home 
when robbed. Two scales were created, consisting of the number of family members who had experienced these nine incidents and a similar count of the number of friends who had been victimized.

Children's fear of crime was measured with two standard National Crime Survey items: "How safe would you feel being out alone in your neighborhood during the day?" and "How safe would you feel being out alone in your neighborhood at night?" Children responded to these questions on a Likert scale that ranged from 1 (very safe) to 4 (very unsafe). A sum of these two items is used as an index of children's fear of crime. Cronbach's alpha for this sample was .65 .

The Child Post-Traumatic Stress Reaction Index (PTSRI) consisted of a 20-item scale patterned after the criteria for PTSD described in the Diagnostic and Statistical Manual of Mental Disorders (DSM-III; American Psychiatric Association, 1980). This measure was developed by Frederick, Pynoos, and Nader and was adapted by Frederick (1985) to identify the presence and severity of PTSD symptomatology in school-aged children and adolescents (Pynoos \& Nader, 1993). The frequency of symptoms was rated on a 5point Likert scale ranging from 0 (none) to 4 (most of the time). Interpretive guidelines classify scores into mild, moderate, severe, and very severe levels of PTSD. When administered by clinicians, Pynoos and colleagues (1993) reported excellent interitem agreement, with a Cohen's kappa of .88. Goenjian and colleagues (1995) reported that the combined severe and very severe categories correctly identified $78 \%$ of the children who met DSM-III-R (American Psychiatric Association, 1987) criteria for PTSD. In our sample, $40 \%$ of the children scored in the moderate PTSD range, and $20 \%$ scored in the severe and very severe categories. The Cronbach's alpha for our sample was .88 , with higher scores indicating the presence of more PTSD symptoms.

The Survey of Children's Stress SymptomsParent Report is a 27-item scale evaluating child behaviors and feelings that are indicative of psychological distress (Pynoos, Rodriguez, Steinberg, Stuber, \& Frederick, 1998). Examples of child behaviors and emotions included in this measure are safety concerns, sleeping difficulties, and feelings of loneliness. Mothers indicate the extent to which they have observed such things in their children on a scale from 1 (never occurs) to 4 (occurs a lot of the time). Higher scores indicated greater symptoms of distress, and the Cronbach's alpha was .92 .
The Child Behavior Checklist-Parent Report (CBCL; Achenbach, 1991) is a well-standardized, widely used 119-item instrument that measures the type and severity of a child's internalizing and externalizing problem behaviors. Mothers rate their children's problem behavior on a 3-point scale, from 0 (not true) to 2 (often true), for the previous 6 months. For the purposes of this study, we used the externalizing and internalizing subscales of the CBCL. The internalizing scale is composed of problems regarding anxiety, social withdrawal, and somatic complaints; externalizing behavior problems include aggression, hyperactivity, and delinquency. Satisfactory test-retest correlations indicate stability in symptom patterns, and discriminant validity is demonstrated by highly significant differences between normal and clinical subjects on all of the scales (Achenbach). In our sample, both the externalizing and internalizing subscales had alphas of .90 .

\section{RESULTS}

In keeping with numerous studies, the children in this sample were exposed to especially high amounts of community violence at a young age. Children's lifetime exposure rates to different types of violence are illustrated in Table 2. Over one quarter of the sample reported that they had seen another person stabbed with a knife or shot with a gun. More than half of the children saw a seriously wounded person after a violent incident, and $44 \%$ of the sample reported that they had themselves been threatened with serious physical harm. Also in accord with other findings, children's rate of witnessing violence was higher than their rate of personal experiences with victimization. Not surprisingly, experiences of personal victimization were greater for boys as compared to girls $(t=3.07, p<.01)$. Mean levels of personal victimization were 16.21 for boys and 7.91 for girls. Similar gender differences emerged with regard to witnessing community violence. Mothers' reports of children's personal victimization also varied significantly by gender of the child in the same manner as that reported by the children themselves.

Prevalence rates for children's lifetime exposure to violent incidents, based on mothers' reports, are also presented in Table 2. Group-level comparisons of mother and child reports were conducted with $\chi^{2}$ analyses. The resulting $\chi^{2}$ values are shown in Table 2. For each type of violent incident, mothers' dichotomous answers (yes/no) 
Table 2. Children's Violence Exposure: Comparison of Child and Mother Reports

\begin{tabular}{|c|c|c|c|c|}
\hline Type of Violence & $\begin{array}{c}\text { Child's } \\
\text { Report } \\
(\%)\end{array}$ & $\begin{array}{c}\text { Mother's } \\
\text { Report } \\
(\%)\end{array}$ & $x^{2}$ & $\kappa$ \\
\hline \multicolumn{5}{|l|}{ Personal victimization } \\
\hline Heard sound of gunfire & 89 & 97 & $4.82 *$ & .12 \\
\hline Slapped, punched, or hit by another & 65 & 39 & $13.71 * * *$ & $.28 * * *$ \\
\hline Threatened with serious physical harm & 44 & 18 & $15.32 * * *$ & .07 \\
\hline Chased by gangs & 26 & 10 & $9.31 * *$ & .15 \\
\hline Beaten up or mugged & 24 & 7 & $11.99 * * *$ & .09 \\
\hline At home when burglarized & 21 & 11 & $4.24 *$ & -.02 \\
\hline Seen or heard gun fired in home & 21 & 8 & $7.48 * *$ & $.17 *$ \\
\hline Asked to sell drugs & 14 & 1 & $11.88 * * *$ & -.02 \\
\hline Attacked or stabbed with a knife & 13 & 0 & $13.74 * * *$ & —a \\
\hline Shot at with a gun & 11 & 2 & $6.56^{* *}$ & .13 \\
\hline \multicolumn{5}{|l|}{ Witnessing violence } \\
\hline Seen other threatened with physical harm & 66 & 46 & $8.60 * *$ & $.25^{* *} *$ \\
\hline Seen other beaten up or mugged & 65 & 42 & $11.63 * * *$ & .15 \\
\hline Seen other carrying a gun or a knife & 55 & 44 & 2.59 & $.20 *$ \\
\hline Seen others use or sell drugs & 53 & 42 & 2.62 & $.22 *$ \\
\hline Seen seriously wounded person & 52 & 31 & $9.52^{* *}$ & .12 \\
\hline Seen other stabbed with a knife & 32 & 6 & $22.42 * * *$ & .01 \\
\hline Seen dead person in community & 26 & 16 & $3.56(p=.06)$ & .17 \\
\hline Seen other get shot with a gun & 25 & 13 & $5.35 *$ & $.25^{* *}$ \\
\hline Seen other committing suicide & 23 & 0 & $27.16^{* * *}$ & —a \\
\hline Seen person killed by another & 16 & 4 & $8.12 * *$ & .04 \\
\hline
\end{tabular}

${ }^{a}$ Kappa statistics cannot be computed because the data did not conform to a symmetrical two-way table.

$* p<.05 . * * p<.01 . * * * p<.001$.

for their children's exposure were compared to dichotomous (at least once/never) recodings of the children's answers to each question. On the whole, the results indicate that mothers significantly underestimated children's personal victimization and witnessing of violence in their community. For instance, compared to their mothers, children were more than twice as likely to report that they had been chased by gangs and more than three times more likely to report that they had been beaten up or mugged. Whereas $32 \%$ of the children reported that they had seen another person stabbed with a knife, only $6 \%$ of the mothers reported that their children had ever been exposed to such an incident. Further, only $1 \%$ of the mothers reported that their children had ever been asked to sell drugs, but $14 \%$ of the children endorsed this item.

Cohen (1960) postulated that a $\chi^{2}$ analysis offers researchers a statistic of association that can reveal the extent to which people disagree at a rate significantly greater than chance. Alternatively, Cohen recommended the use of a kappa statistic for evaluations of agreement. Content analysis researchers typically accept kappa statistics above .74 as indicators of excellent interrater reliability (Meyer, 1999). Consequently, kappa statistics are provided in Table 2 to assess congruence between mother and child reports on each type of violent event. In general, the kappa statistics between mother and child reports are all rather low, below .30 , providing support for the $\chi^{2}$ findings that there is generally low agreement between reports from mothers and children on specific incidents of violence exposure. On six incidents, however, we found significant kappa statistics, indicating that although mother and child agreement was relatively low, there was nonetheless a better than chance agreement on certain violence exposure items.

Chi-squared analyses were used to conduct similar group-level comparisons of mother and child reports on children's PTSD symptoms. Fifteen items from the PTSRI matched questions on the parent-completed Survey of Children's Stress Symptoms. For each item, mother and child reports were recoded into a dichotomous score of 1 (yes) or 0 (no). Mothers' reports of the frequency of children's psychological symptoms were not considered in this analysis; instead, mother and child reports on the simple presence or absence of a symptom were compared. The results of these comparisons are illustrated in Table 3 . Once again, mothers generally underestimated their children's experiences of psychological distress. Whereas 
Table 3. Children's Posttraumatic Stress Disorder (PTSD) Symptoms: Comparison of Child And Mother REPORTS

\begin{tabular}{|c|c|c|c|c|}
\hline PTSD Symptom & $\begin{array}{c}\text { Child's } \\
\text { Report } \\
(\%)\end{array}$ & $\begin{array}{c}\text { Mother's } \\
\text { Report } \\
(\%)\end{array}$ & $\chi^{2}$ & $\kappa$ \\
\hline Sick feelings (e.g., stomachaches or headaches) & 88 & 53 & $28.16 * * *$ & .04 \\
\hline Bad dreams & 83 & 50 & $24.91 * * *$ & .04 \\
\hline Scared and afraid when reminded of past & 78 & 85 & 1.53 & -.07 \\
\hline Trouble sleeping & 76 & 37 & $31.69 * * *$ & .06 \\
\hline Feel lonely inside or alone with feelings & 76 & 57 & $7.94 * *$ & $.18 *$ \\
\hline Feel guilty for something not done in past & 75 & 37 & $28.69 * * *$ & -.09 \\
\hline Upsetting thoughts about past enter mind & 73 & 45 & $15.05 * * *$ & $.27 * *$ \\
\hline Startle easily or feel jumpy & 72 & 63 & 1.96 & .05 \\
\hline Avoid reminders of a past event & 71 & 31 & $30.79 * * *$ & .10 \\
\hline Feel numb & 71 & 42 & $16.79 * * *$ & $-.16^{*}$ \\
\hline Feel too scared to talk or cry & 65 & 50 & $4.75^{*}$ & .02 \\
\hline Difficulty paying attention & 65 & 61 & .23 & .13 \\
\hline Hard to keep self from getting into fighting & 61 & 51 & 2.31 & .04 \\
\hline Fear that bad things might happen again & 56 & 28 & $15.61 * * *$ & .06 \\
\hline Dislike things that were once pleasurable & 53 & 51 & .12 & .13 \\
\hline
\end{tabular}

$* p<.05 . * * p<.01 . * * * p<.001$.

$75 \%$ or more of the children reported experiencing sick feelings, bad dreams, loneliness, and guilt about the past, less than $60 \%$ of the mothers reported that their children were experiencing each of these items. Further, $71 \%$ of the children reported that they avoided reminders of a past event, but only $31 \%$ of mothers endorsed this item for their children. Kappa statistics assessing the levels of congruence between mother and child reports similarly indicated that there was a minimal level of agreement about children's PTSD symptoms. As shown in Table 3, significant kappa statistics emerged for just 3 of the 15 items.

Using the summary measures of mother-child agreement on personal victimization and witnessing violence, $t$ tests were conducted to explore how individual child and parent characteristics may be related to mothers' knowledge of their children's violence exposure. Mother-child agreement on children's personal victimization was higher with female children as compared to male children, with means of 8.09 and 6.96, respectively $(t=-3.07, p<.01)$. Mothers were also in greater agreement about the violence exposure, both personal victimization and witnessing violence, reported by their younger, mostly 9 -yearold children in comparison to their older 10- and 11-year-olds. Analyses of variance were conducted to test for age by gender interactions, but interaction terms were not significant. Finally, mothers' age (median split), employment, marital status, educational level (high school degree vs. no degree), and number of children (median split) were not related to mother-child concordance on reports of children's exposure to violence. Only one parental characteristic reached marginal significance in relation to mother-child congruence. Mothers who were not born in the United States had higher levels of agreement with children's reports of personal victimization compared to mothers born in the United States, with means equal to 8.09 and 7.31, respectively $(t=1.92, p=.06)$.

Hierarchical regression analyses were used to test our hypotheses about predictors of children's psychological well-being. We proposed that greater exposure to violence, greater fear of crime, and more vicarious violence exposure would be associated with higher levels of psychological distress, specifically manifested in increased levels of PTSD and externalizing and internalizing problem behaviors. For the exposure to violence measures, the scales of personal victimization and witnessing violence were highly correlated among both children and mothers $(r=.76, p<.001$, and $r=$ $.58, p<.001$, respectively). These scales were thus not entered into the same regression equation to avoid multicollinearity. Additionally, we predicted that mothers' reports of children's violence exposure and mother-child agreement about children's exposure to violence would be similarly related to the indicators of children's mental health.

Although it may seem reasonable to treat the mother-child dyad as the unit of statistical analysis (Maguire, 1999), this approach was not warranted in the current study for two reasons. First, we are not attempting to estimate a latent interdependent 
Table 4. Hierarchical Regression Analyses Predicting Children's Well-Being With Child Predictors $(N=104)$

\begin{tabular}{|c|c|c|c|c|c|c|}
\hline \multirow[b]{2}{*}{ Predictor Variables } & \multicolumn{2}{|c|}{$\begin{array}{c}\text { Posttraumatic } \\
\text { Stress Disorder }\end{array}$} & \multicolumn{2}{|c|}{$\begin{array}{l}\text { Externalizing } \\
\text { Symptoms }\end{array}$} & \multicolumn{2}{|c|}{ Internalizing Symptoms } \\
\hline & $\beta$ & SE B & $\beta$ & SE B & $\beta$ & SE B \\
\hline \multicolumn{7}{|l|}{ Step 1} \\
\hline Child's age & .14 & 1.58 & -.01 & 1.05 & .01 & 1.00 \\
\hline Child's gender $($ male $=0 /$ female $=1)$ & -.06 & 2.79 & -.18 & 1.86 & -.03 & 1.78 \\
\hline \multicolumn{7}{|l|}{ Child's race } \\
\hline African American & .12 & 4.63 & -.08 & 3.07 & .06 & 2.94 \\
\hline Latino & -.04 & 3.46 & .02 & 2.31 & .16 & 2.21 \\
\hline Mother's age & .05 & 0.19 & -.04 & 0.13 & -.06 & 0.12 \\
\hline \multicolumn{7}{|l|}{ Mother born in United States } \\
\hline$($ no $=0 /$ yes $=1)$ & $.32 * *$ & 3.15 & $.21 *$ & 2.10 & -.19 & 2.01 \\
\hline \multicolumn{7}{|l|}{ Mother's marital status (not married } \\
\hline$F=0 /$ married $=1)$ & $3.05^{* *}$ & 2.70 & $\begin{array}{r}-.13 \\
1.64\end{array}$ & 1.80 & $\begin{array}{r}-.13 \\
1.27\end{array}$ & 1.72 \\
\hline$R^{2}$ & .18 & & .11 & & .09 & \\
\hline \multicolumn{7}{|l|}{ Step 2} \\
\hline Child's age & .10 & 1.55 & -.06 & 1.01 & -.03 & 0.98 \\
\hline Child's gender & .02 & 2.89 & -.06 & 1.89 & .08 & 1.85 \\
\hline \multicolumn{7}{|l|}{ Child's race } \\
\hline African American & $.24 *$ & 4.77 & .04 & 3.11 & .16 & 3.03 \\
\hline Latino & .08 & 3.62 & .11 & 2.37 & .22 & 2.31 \\
\hline Mother's age & .04 & 0.19 & -.06 & 0.12 & -.08 & 0.12 \\
\hline Mother born in United States & $.21 *$ & 3.22 & .10 & 2.11 & $-.29 *$ & 2.05 \\
\hline Mother's marital status & .11 & 2.80 & $-.24 *$ & 1.84 & $-.22 *$ & 1.79 \\
\hline Personal victimization & $.29^{*}$ & 0.14 & $.41 * *$ & 0.09 & $.39 * *$ & 0.09 \\
\hline Fear of crime & .00 & 1.65 & -.17 & 1.08 & -.14 & 1.05 \\
\hline Vicarious victimization: friends & -.16 & 0.14 & -.23 & 0.09 & -.24 & 0.09 \\
\hline Vicarious victimization: family & .20 & 0.38 & .18 & 0.25 & .12 & 0.24 \\
\hline$F$ & $3.00 * *$ & & $2.41 * *$ & & 1.76 & \\
\hline$R^{2}$ & .26 & & .23 & & .18 & \\
\hline
\end{tabular}

$* p<.05 . * * p<.01$.

construct that shares a dyadic and an individual component (Gonzalez \& Griffin, 2000). A dyadic approach is best suited for questions that involve interdependence between people, such as predictions about couples who feel more or less affection for each other. Our questions do not concern interdependence between mothers' and children's experiences but rather focus on comparisons of mother and child reports about objective, environmental incidents. Second, the use of an actor-partner regression model is not appropriate for our present study in that we are not concerned with predicting maternal well-being and a combined effect between mother's and child's well-being (Gonzalez \& Griffin). However, mothers' reports of their children's personal victimization were positively correlated with children's reports of personal victimization $(r=.37, p<.001)$, and mother-child congruence on personal victimization was significantly correlated with children's personal victimization $(r=-.55, p<.001)$. In order to avoid multicollinearity and any potential confounding of nonindependent observations from mothers and children, maternal and child predictors concerning violence exposure were tested in separate regressions.

In the first set of hierarchical regressions, six demographic controls were entered in the first step of each equation, including children's age, gender, and race and mothers' age, immigrant status, and marital status. Two dummy variables were created to control for children's race with an African American variable coded 1 for African American children and 0 for all other races and a Latino variable coded 1 for Latino children and 0 for all others. The child predictors of personal victimization, fear of crime, and the vicarious victimization of friends and family were included in the second step. The results of three regression equations, using these variables to predict PTSD symptoms and externalizing and internalizing behavior problems, are presented in Table 4. As expected, 
Table 5. Hierarchical Regression Analyses Predicting Children's Well-Being With Maternal Predictors $(N=104)$

\begin{tabular}{|c|c|c|c|c|c|c|}
\hline \multirow[b]{2}{*}{ Predictor Variables } & \multicolumn{2}{|c|}{$\begin{array}{l}\text { Posttraumatic Stress } \\
\text { Disorder }\end{array}$} & \multicolumn{2}{|c|}{$\begin{array}{l}\text { Externalizing } \\
\text { Symptoms }\end{array}$} & \multicolumn{2}{|c|}{$\begin{array}{l}\text { Internalizing } \\
\text { Symptoms }\end{array}$} \\
\hline & $\beta$ & SE B & $\beta$ & SE B & $\beta$ & SE B \\
\hline \multicolumn{7}{|l|}{ Step 1} \\
\hline Child's age & .14 & 1.58 & -.01 & 1.05 & .01 & 1.00 \\
\hline \multicolumn{7}{|l|}{ Child's race } \\
\hline African American & .11 & 4.64 & -.08 & 3.07 & .06 & 2.94 \\
\hline Latino & -.03 & 3.48 & .02 & 2.31 & .16 & 2.21 \\
\hline Mother's age & .05 & 0.19 & -.04 & 0.13 & -.06 & 0.12 \\
\hline $\begin{array}{l}\text { Mother born in United States } \\
(\text { no }=0 / \text { yes }=1)\end{array}$ & $.33 * *$ & 3.17 & .21 & 2.10 & -.19 & 2.01 \\
\hline $\begin{array}{l}\text { Mother's marital status (not married } \\
=0 / \text { married }=1 \text { ) }\end{array}$ & $.19^{*}$ & 2.72 & -.13 & 1.80 & -.13 & 1.72 \\
\hline$F$ & $3.02 * *$ & & 1.64 & & 1.27 & \\
\hline$R^{2}$ & .18 & & .11 & & .09 & \\
\hline \multicolumn{7}{|l|}{ Step 2} \\
\hline Child's age & .13 & 1.60 & -.12 & 0.98 & -.09 & 0.95 \\
\hline Child's gender & .04 & 2.96 & -.06 & 1.81 & .11 & 1.75 \\
\hline \multicolumn{7}{|l|}{ Child's race } \\
\hline African American & .11 & 4.61 & -.01 & 2.82 & .12 & 2.73 \\
\hline Latino & -.04 & 3.44 & .07 & 2.10 & .19 & 2.04 \\
\hline Mother's age & .06 & 0.19 & .00 & 0.12 & -.02 & 0.11 \\
\hline Mother born in United States & $.28 *$ & 3.27 & .06 & 2.00 & $-.34 * *$ & 1.94 \\
\hline Mother's marital status & .18 & 2.69 & -.11 & 1.64 & -.12 & 1.59 \\
\hline $\begin{array}{l}\text { Child's personal victimization } \\
\text { (mother report) }\end{array}$ & .00 & 1.20 & $.43 * * *$ & 0.74 & $.36^{* * * *}$ & 0.71 \\
\hline Mother-child agreement & & & & & & 0 \\
\hline$F$ & $\begin{array}{l}-.24 * \\
3.05 * *\end{array}$ & 0.79 & $\begin{array}{l}-.14 \\
4.07 * * *\end{array}$ & 0.48 & $\begin{array}{l}-.22^{*} \\
3.34 * * *\end{array}$ & 0.47 \\
\hline$R^{2}$ & .23 & & .28 & & .24 & \\
\hline
\end{tabular}

$* p<.05 . * * p<.01 . * * * p<.001$.

personal victimization was a significant predictor of all three indicators of children's well-being, such that children who reported more experiences of victimization had greater PTSD, externalizing, and internalizing symptoms $(\beta=.29, p<.05 ; \beta$ $=.41, p<.01$; and $\beta=.39, p<.01$, respectively). African American children reported higher levels of PTSD symptoms $(\beta=.24, p<.05)$, and married mothers indicated that their children had fewer externalizing and internalizing problem behaviors $(\beta=-.24, p<.05$, and $\beta=-.22, p$ $<.05$, respectively). Finally, children of immigrant mothers reported fewer PTSD symptoms ( $\beta$ $=.21, p<.05$ ) and more internalizing symptoms $(\beta=-.29, p<.05)$. Surprisingly, however, children's fear of crime and vicarious victimization were not significant predictors of children's psychological well-being. If witnessing violence is entered into the regressions in place of personal victimization, it is similarly related to PTSD symptoms but is not associated with externalizing or internalizing problem behaviors.

Results from the second set of regression equations are illustrated in Table 5. The same demographic controls were entered in the first step of these regressions, followed by the inclusion of mother's report of child's personal victimization and mother-child agreement on child's victimization experiences in the second step. As predicted, mother's report of child's personal victimization was positively linked to both externalizing ( $\beta=$ $.43, p<.001)$ and internalizing problems $(\beta=$ $.36, p<.001)$ in children. Also, in confirmation of our hypotheses, higher levels of mother-child concordance regarding children's victimization experiences were significantly associated with fewer PTSD symptoms $(\beta=-.24, p<.05)$ and internalizing behavior problems $(\beta=-.22, p<$ $.05)$. Finally, children of immigrant mothers reported less PTSD and more internalizing symp- 
toms. When mother's report of child's witnessing violence and mother-child agreement on children's experiences of witnessing violence were alternatively included as predictors, similar results emerged.

\section{DisCUSSION}

Consistent with other findings in the literature, the children in the present study were exposed to rather high levels of community violence (Bell \& Jenkins, 1991; Richters \& Martinez, 1993; SchwabStone et al., 1999; Singer et al., 1995). Eighty-nine percent of the children reported that they regularly heard the sound of gunfire, and over a quarter of the children reported having seen someone else stabbed with a knife or shot with a gun. Several studies found that male children are more involved in street-culture activities than their female counterparts in inner-city neighborhoods (Fitzpatrick \& Boldizar, 1993; Gladstein et al., 1992). Similarly, in our sample, boys reported more encounters with urban violence than did girls. Compared to boys, mothers and their female children reported greater agreement about girls' personal victimization experiences. Because girls are less involved in street-culture activities, it may be easier for mothers to supervise their activities (Bell \& Jenkins, 1993; Fitzpatrick \& Boldizar). Mothers were also in greater agreement about violence exposure with their younger, as opposed to older, children. Likewise, it may be easier for mothers to monitor the activities of younger children. Crouter and colleagues (1999) similarly report that middle-class mothers have more knowledge about the activities of their younger children and children of their same sex.

Relatively little attention has focused on the extent of parental knowledge about children's encounters with and psychological reactions to community violence. In our study, there was little agreement between mother and child reports of children's PTSD symptoms. Mothers typically underestimated children's experiences of psychological distress. Other researchers similarly found little agreement between mother and child reports of children's self-reported symptoms of psychological distress (Angold et al., 1987; Richters \& Martinez, 1993; Williams, McGee, Anderson, \& Silva, 1989). Not surprisingly, parents tend to be more aware of their children's more visible, externalizing behaviors than their internalizing symptoms (Williams et al.).

In comparing children's reports of violence exposure to parental accounts, our results essentially mirror those of Richters and Martinez (1993) and Hill and Jones (1997). Our analyses indicate that mothers generally underestimate children's exposure to many different types of violence. The causes behind these discrepancies are most likely multiply determined. First, children may consciously keep such information from their parents in order to ward off the restrictions that might accompany greater parental awareness. Second, parents may choose to cope with environmental obstacles by repressing, ignoring, or denying their existence. It may, for example, be quite difficult for parents who exercise many precautions to admit that their children are nonetheless exposed to traumatic urban violence. Third, children may not discuss their experiences with violence because such violence has become somewhat commonplace in their lives. Apathy and desensitization to violence are commonly reported reactions for both children and parents (Hill \& Jones; Lorion \& Saltzman, 1993). Finally, children may keep their experiences and emotional reactions private in order to protect their parents from emotional pain.

Yet another interpretation of these findings is that children are, to some extent, exaggerating their experiences with community violence and that parents are intentionally underreporting children's violence exposure. It is important to note that a great deal of care was taken to ensure that children independently answered their questionnaires and that both children and parents understood that our questions about violence exposure did not refer to violence depicted in the media. Although some children may have reasons to exaggerate their responses, mothers did corroborate children's reports of encounters with six violent incidents. Hence, researchers investigating children's exposure to violence may be well advised to incorporate reports from both parents and children in order to provide the richest picture of children's encounters with violence (Hill \& Jones, 1997). It seems counterproductive to confront either children or parents in an attempt to reconcile their divergent accounts into one "truth" when the reality of their experiences may be more complicated. Children and parents may have different interpretations of the same violent event (Larson \& Richards, 1994; Shahinfar, Fox, \& Leavitt, 2000).

Consistent with prior research, exposure to violence was associated with greater psychological distress, specifically manifested in PTSD and in externalizing and internalizing symptoms (Hill \& Madhere, 1996; Pynoos \& Nader, 1990, 1988; 
Schwab-Stone et al., 1999; Singer et al., 1995). Experiences with both personal victimization and witnessing violence were associated with poorer psychological functioning. Additionally, no consistently significant racial differences emerged. On the whole, our multiethnic sample suggests that the detrimental risks associated with community violence are present for all children, irrespective of their racial background. In this case, the weighty impact of dangerous contextual surroundings may overpower the influence of culturally specific family differences. Compared to mothers who were not married, mothers with spouses reported fewer behavior problems in their children. Children may directly benefit from the resources provided by an additional parent, or they may indirectly benefit from mothers who receive greater instrumental and emotional support.

As expected, mothers' reports of children's violence exposure are also related to children's symptoms of psychological distress. This finding further affirms the importance of attending to both parent and child reports of violence exposure. Moreover, greater mother-child agreement about children's violence exposure is associated with diminished PTSD and internalizing symptoms. This suggests that there may be a beneficial impact for children who have the opportunity to talk about community violence with their parents. In these situations, parents may help children express their feelings, normalize their reactions to violence, and construct safety plans for the future. Alternatively, parents who are unaware of the extent of violence encountered by their children may miss opportunities to counsel their children about how to cope with violence. Results regarding mothers' immigrant status were inconsistent, perhaps because we used a rather global measure of immigration without accounting for the specifics of acculturation and other such factors.

Although our findings indicate that the psychological repercussions of urban violence are detrimental to children, parents may have an important protective role to play in buffering children from the effects of violence. These findings underscore the importance of involving parents in intervention efforts that counter the adverse impact of environmental adversities. Support groups in which both mothers and children participate together may reduce the lack of congruence between mother and child reports and increase parent-child communication, improving children's ability to cope with the emotional aftermath of violent trauma.
We must note that the cross-sectional nature of our data cannot confirm any direction of causality, and our reliance on a sample of convenience limits the generalizability of our findings. However, because violence is not a randomly distributed problem in our society, the benefits of a randomly distributed sample to study these issues may be questionable (Fitzpatrick, 1993). Another limitation for the current study concerns the possibility of selection effects. The most efficacious and involved parents may enroll their children in one of two private, parochial schools in the neighborhood. Our findings are thus preliminary and await replication by future researchers.

The present study contributes to the literature on children's exposure to community violence by using a multiethnic sample of families and analyzing how mother-child agreement on violence exposure influences children's psychological wellbeing. For researchers, the question of how to utilize and reconcile divergent parent and child accounts is an important area for future study. Further, it is important to identify individual characteristics and family-level processes that can buffer children from the harmful effects of urban violence. Other areas for future research include investigating the role fathers play in helping children cope with violence and the situation faced by the many children who simultaneously encounter community violence and domestic violence within their homes.

\section{Note}

This research was supported by funds provided by the Department of Psychology and the Center for Human Growth and Development at the University of Michigan. We are most grateful for the openness and generosity of the mothers and children who shared their experiences with us. In addition, we would like to thank members of the Study Group on Culture and Ethnicity, a subgroup of the Family Research Consortium, for constructive and insightful comments on earlier drafts of this paper. We are also appreciative of the responsive and sound statistical advice provided by Richard Gonzalez and David Winter. Finally, we would like to acknowledge a large group of talented and dedicated undergraduate students who assisted with data collection and data entry.

\section{REFERENCES}

Achenbach, T. M. (1991). Manual for the Child Behavior Checklist/4-18 and the 1991 profile. Burlington: University of Vermont.

American Psychiatric Association. (1980). Diagnostic and statistical manual of mental disorders (3rd ed.). Washington, DC: Author.

American Psychiatric Association. (1987). Diagnostic 
and statistical manual of mental disorders (3rd ed., rev.). Washington, DC: Author.

Angold, A., Weissman, M. M., John, K., Merikangas, K. R., Prusoff, B. A., Wickramaratne, P., Gammon, G. D., \& Warner, V. (1987). Parent and child reports of depressive symptoms in children at low and high risk of depression. Journal of Child Psychology and Psychiatry, 28, 901-915.

Baldwin, A. L., Baldwin, C., \& Cole, R. E. (1990). Stress-resistant families and stress-resistant children. In J. Rolf, A. S. Masten, D. Cicchetti, K. H. Nuechterlein, \& S. Weintraub (Eds.), Risk and protective factors in the development of psychopathology (pp. 257-280). Cambridge, U.K.: Cambridge University Press.

Bell, C. C., \& Jenkins, E. J. (1991). Traumatic stress and children. Journal of Health Care for the Poor \& Underserved, 2, 175-185.

Bell, C. C., \& Jenkins, E. J. (1993). Community violence and children on Chicago's southside. Psychiatry, 56, 46-54.

Bronfenbrenner, U. (1986). Ecology of the family as a context for human development: Research perspectives. Developmental Psychology, 22, 723-742.

Cohen, J. (1960). A coefficient of agreement for nominal scales. Educational and Psychological Measurement, 20, 37-46.

Cooley-Quille, M. R., Turner, S. M., \& Beidel, D. C. (1995). Emotional impact of children's exposure to community violence: A preliminary study. Journal of the American Academy of Child and Adolescent Psychiatry, 34, 1362-1368.

Crouter, A. C., Helms-Erikson, H., Updegraff, K., \& McHale, S. M. (1999). Conditions underlying parents' knowledge about children's daily lives in middle childhood: Between- and within-family comparisons. Child Development, 70, 246-259.

Crouter, A. C., MacDermid, S. M., McHale, S. M., \& Perry-Jenkins, M. (1990). Parental monitoring and perceptions of children's school performance and conduct in dual- and single-earner families. Developmental Psychology, 26, 649-657.

DuRant, R. H., Getts, A., Cadenhead, C., Emans, S. J., \& Woods, E. R. (1995). Exposure to violence and victimization and depression, hopelessness, and purpose in life among adolescents living in and around public housing. Developmental and Behavioral Pediatrics, 16, 233-237.

Federal Bureau of Investigation. (1997). Violent crimes. In Uniform crime statistics [On-line]. Available: http:// www.fbi.gov/ucr.htm

Fitzpatrick, K. M. (1993). Exposure to violence and presence of depression among low-income, African American youth. Journal of Consulting and Clinical Psychology, 61, 528-531.

Fitzpatrick, K. M., \& Boldizar, J. P. (1993). The prevalence and consequences of exposure to violence among African-American youth. Journal of the American Academy of Child and Adolescent Psychiatry, 32, 424-430.

Frederick, C. J. (1985). Selected foci in the spectrum of post-traumatic stress disorders. In J. Laube \& S. A. Murphy (Eds.), Perspectives on disaster recovery (pp. 110-130). Norwalk, CT: Appleton-CenturyCrofts.

Gladstein, J., Rusonis, E., \& Heald, F. P. (1992). A com- parison of inner-city and upper-middle class youths' exposure to violence. Journal of Adolescent Health, 13, 275-280.

Goenjian, A. K., Pynoos, R. S., Steinberg, A. M., Najarian, L. M., Asarnow, J. R., Karayan, I., Ghurabi, M., \& Fairbanks, L. A. (1995). Psychiatric co-morbidity in children after the 1988 earthquake in Armenia. Journal of the American Academy of Child and Adolescent Psychiatry, 34, 1174-1184.

Gonzalez, R., \& Griffin, D. (2000). On the statistics of interdependence: Treating dyadic data with respect. In W. Ickes \& S. Duck (Eds.), The social psychology of personal relationships (pp. 181-213). New York: Wiley.

Gorman-Smith, D., \& Tolan, P. (1998). The role of exposure to community violence and developmental problems among inner-city youth. Development and Psychopathology, 10, 101-116.

Gorman-Smith, D., Tolan, P. H., Zelli, A., \& Huesmann, L. R. (1996). The relation of family functioning to violence among inner-city minority youths. Journal of Family Psychology, 10, 115-129.

Hill, H. M., \& Jones, L. P. (1997). Children's and parents' perceptions of children's exposure to violence in urban neighborhoods. Journal of the National Medical Association, 89, 270-276.

Hill, H. M., \& Madhere, S. (1996). Exposure to community violence and African American children: A multidimensional model of risks and resources. Journal of Community Psychology, 24, 26-43.

Jenkins, E. J., \& Bell, C. C. (1994). Violence among inner city high school students and post-traumatic stress disorder. In E. J. Jenkins \& C. C. Bell (Eds.), Anxiety disorders in African Americans (pp. 76-88). New York: Springer.

Larson, R., \& Richards, M. H. (1994). Divergent realities: The emotional lives of mothers, fathers and adolescents. New York: Basic Books.

Lorion, R. P., \& Saltzman, W. (1993). Children's exposure to community violence: Following a path from concern to research to action. Psychiatry, 56, 55-65.

Maguire, M. C. (1999). Treating the dyad as the unit of analysis: A primer on three analytic approaches. Journal of Marriage and the Family, 61, 213-223.

Martinez, P., \& Richters, J. E. (1993). The NIMH community violence project: II. Children's distress symptoms associated with violence exposure. Psychiatry, 56, 22-35.

Mason, C. A., Cauce, A. M., Gonzales, N., \& Hiraga, Y. (1996). Neither too sweet nor too sour: Problem peers, maternal control, and problem behavior in African American adolescents. Child Development, 67, 2115-2130.

McLoyd, V. C., \& Ceballo, R. (1998). Conceptualizing and assessing economic context: Issues in the study of race and child development. In V. C. McLoyd \& L. Steinberg (Eds.), Studying minority adolescents: Conceptual, methodological, and theoretical issues (pp. 251-278). Mahwah, NJ: Erlbaum.

Meyer, G. J. (1999). Simple procedures to estimate chance agreement and kappa for the interrater reliability of response segments using the Rorschach comprehensive system. Journal of Personality Assessment, 72, 230-255.

Pettit, G. S., Bates, J. E., Dodge, K. A., \& Meece, D. W. (1999). The impact of after-school peer contact 
on early adolescent externalizing problems is moderated by parental monitoring, perceived neighborhood safety, and prior adjustment. Child Development, 70, 768-778.

Pynoos, R. S., Goenjian, A., Tashjian, M., Karakashian, M., Manjikian, R., Manoukian, G., Steinberg, A. M., \& Fairbanks, L. A. (1993). Post-traumatic stress reactions in children after the 1988 Armenian earthquake. British Journal of Psychiatry, 163, 239-247.

Pynoos, R. S., \& Nader, K. (1988). Psychological first aid and treatment approaches to children exposed to community violence: Research implications. Journal of Traumatic Stress, 1, 445-473.

Pynoos, R. S., \& Nader, K. (1990). Children's exposure to violence and traumatic death. Psychiatric Annals, 20, 334-344.

Pynoos, R. S., \& Nader, K. (1993). Child PTSD Reaction Index. Unpublished test, University of California at Los Angeles.

Pynoos, R., Rodriguez, N., Steinberg, A., Stuber, M., \& Frederick, C. (1998). The Survey of Children's Stress Symptoms. Unpublished test, University of California at Los Angeles.

Richters, J. E., \& Martinez, P. (1993). The NIMH community violence project: I. Children as victims of and witnesses to violence. Psychiatry, 56, 7-21.

Schwab-Stone, M., Chen, C., Greenberger, E., Silver,
D., Lichtman, J., \& Voyce, C. (1999). No safe haven: II. The effects of violence exposure on urban youth. Journal of the American Academy of Child and Adolescent Psychiatry, 38, 359-367.

Shahinfar, A., Fox, N. A., \& Leavitt, L. A. (2000). Preschool children's exposure to violence: Relation of behavior problems to parent and child reports. American Journal of Orthopsychiatry, 70, 115-125.

Singer, M. I., Anglin, T. M., Song, L., \& Lunghofer, L. (1995). Adolescents' exposure to violence and associated symptoms of psychological trauma. Journal of the American Medical Association, 273, 477-482.

U.S. Census Bureau. (1990). Population profile. In 1990 Census of Population and Housing [On-line]. Available: http://www.census.gov

U.S. Census Bureau. (1999). The Hispanic population in the United States: Population characteristics. In Current Population Reports [On-line]. Available: http://www.census.gov

Williams, S., McGee, R., Anderson, J., \& Silva, P. A. (1989). The structure and correlates of self-reported symptoms in 11-year-old children. Journal of Abnormal Child Psychology, 17, 55-71.

Zayas, L. H., \& Solari, F. (1994). Early childhood socialization in Hispanic families: Context, culture, and practice implications. Professional Psychology: Research and Practice, 25, 200-206. 